\title{
Study of a Non-destructive Method for Estimating the Leaf Area Index in Vegetable Crops Using Digital Images
}

\author{
Carlos Campillo ${ }^{1}$ \\ Centro de Investigación Finca La Orden-Valdesequera, Consejería de \\ Economía, Comercio e Innovación, Junta de Extremadura, 06187 Guadajira, \\ Badajoz, Spain
}

\section{M.I. García}

Centro de Investigaciones Agrarias de Mabegondo, Ctra. de BetanzosSantiago km 7.5, 15318 Abegondo A Coruña, Spain

\section{Daza and M.H. Prieto}

Centro de Investigación Finca La Orden-Valdesequera, Consejería de Economía, Comercio e Innovación, Junta de Extremadura, 06187 Guadajira, Badajoz, Spain

Additional index words. LAI, percentage of ground cover, processing tomato, cauliflower

Abstract. One estimate of a crop's ability to capture light energy is the leaf area index (LAI), which is defined as the proportion of leaf area per unit of land area. Direct methods of estimation involve determining the LAI in a significant area of cultivation and individually measuring the leaf surface, which is often tedious. The objective of this study was to develop a cheap and simple method for determining LAI based on the percentage of groundcover (PGC) measured in two vegetable crops with notable differences in leaf type and plant architecture using digital images obtained with a commercial camera and applying open-source software. The PGC values obtained from digital image analysis in cauliflower and tomato crops and the measurements of LAI obtained by destructive sampling (measured with a planimeter) allowed us to obtain a relationship between two variables $\left(r^{2}>0.88\right)$. In all cases, the extinction coefficients were obtained from comparisons of LAI and PGC with values ranging between 0.75 and 0.85 for processing tomato and 0.60 and 0.70 for cauliflower. The method used allows non-destructive estimations of LAI that are comparable with other more expensive indirect methods that require a skilled operator.

The productivity of a crop depends on the ability of plant cover to intercept incident radiation; this is a function of the leaf area available, the architecture of the vegetation cover, and the efficiency of the conversion of energy captured by the plant in the biomass (Gifford et al., 1984). One estimate of a crop's ability to capture light energy is the leaf area index (LAI). The concept of the LAI was first introduced by Watson (1947) and defined as the ratio of leaf area to a given unit of land area.

LAI is the component of crop growth analysis that accounts for the ability of the crop to capture light energy; it is critical for an understanding of the functions of many crop management practices. LAI is important for many areas of agronomy and crop production as a result of its relevance to light interception, crop growth (Pearce et al., 1965),

\footnotetext{
Received for publication 27 Apr. 2010. Accepted for publication 24 July 2010 .

This work was carried out as part of the INIA project RTA04-060-C6 and cofinanced by FEDER. ${ }^{1}$ To whom reprint requests should be addressed; e-mail carlos.campillo@juntaextremadura.net.
}

2004). These methods apply the Beer-Lambert law, taking into account the fact that the total amount of radiation intercepted by a canopy layer depends on the incident irradiance, the canopy structure, and its optical properties (Bréda, 2003). Monsi and Saeki (1953) expanded the Beer-Lambert extinction law to apply it to plant canopies. The Beer-Lambert law expresses the attenuation of radiation in a homogenous turbid medium. In such a medium, the flux is absorbed in proportion to the optical distance. Evaluating LAI by inverting the Beer-Lambert equation requires measurement of both the incident (Io) and below-canopy radiation (I). Following Monsi and Saeki (1953) and with a random distribution of leaves within the canopy:

$$
R I=1-\mathrm{e}^{\left(\left(K^{*} L A I\right)\right)}
$$

where RI is the radiation intercepted by the crop, $\mathrm{k}$ is the extinction coefficient, and LAI is the leaf area index.

The most common method for determining RI is to measure photosynthetically active radiation $(P A R)$ both above and beneath a canopy at approximately solar noon when the light is unobstructed by cloud cover (Board et al., 1992; Egli, 1994). According to Eq. [2]:

$$
R I=\left[1-\left(\frac{(\text { PAR below canopy })}{(\text { PAR above canopy })}\right)\right]
$$

This method involves ground-based measurements of total, direct, and/or diffuse radiation transmittance to the forest floor and it makes use of line quantum sensors or radiometers (Pierce and Running, 1988), laser point quadrats (Wilson, 1963), and capacitance sensors (Vickery et al., 1980). These instruments have already proven their value in estimations of LAI for coniferous (Marshall and Waring, 1986; Pierce and Running, 1988) as well as broad-leafed (Chason et al., 1991) stands. In comparison with allometric methods, the approach provides more accurate LAI estimates (Smith et al., 1991). However, the light measurements required to calculate LAI call for cloudless skies and there is generally a need to incorporate a light extinction coefficient that is both site- and species-specific as a result of leaf angle, leaf form, and leaf clumping, etc. (Vose et al., 1995). Measurements can be taken either by locating the sensors perpendicular to the crop rows (Egli, 1994) or by taking multiple measurements parallel to them (Board et al., 1992). This determination can, however, be costly; it depends on the number of measurements needed to characterize the study area, especially in low-lying crops, where vegetation must be moved to place sensors under it, which implies introducing alterations during data collection.

We therefore determined the percentage of shaded soil at solar noon or percentage of groundcover (PGC), as an estimate of RI, which is the easiest and most economical way (Fakorede and Mock, 1977; Morgan and Brown, 1983; Williams et al., 1965). It is generally assumed that the shaded area at the 
soil level corresponds to the fraction of incident radiation that has been intercepted by the crop. This is an approximation that will remain valid as long as the degree of light transmission through the leaves is small in comparison with its absorption.

The precision with which PGC estimates RI will therefore depend on how well the shaded area is defined and on the capacity of the canopy to capture all of the radiation within the shaded area (Lang et al., 1985). On the other hand, authors like Burstall and Harris (1983), Campillo et al. (2008) and Millard et al. (1990) argue that it is easy to estimate coverage and that it is possible to assume a 1:1 relationship between PGC and $P A R$. Taking advantage of the latest developments in digital technology, it is now possible to measure the evolution of vegetation cover through digital photography and to determine the PGC using image interpretation techniques (Campillo et al., 2008; Rodríguez et al., 2000). This approach could also be used to estimate LAI using Eq. [1]; however, we would need to know the extinction coefficient for each crop and variety (Campbell, 1986). Several authors have discussed how to determine k (Hassika et al., 1997; Ledent, 1977; Smith, 1993; Vose et al., 1995) and the accuracy of methodology to be applied (Nel and Wessman, 1993). It is also important to consider that the extinction coefficient also depends on stand structure and canopy architecture (Smith et al., 1991; Turton, 1985) and that the canopy extinction coefficient is a function of wavelength (Jones, 1992), radiation type, and direction (Berbigier and Bonnefond, 1995). It is also important to maximize spatial integration by using large, linear and/or mobile sensors.

This study aimed to develop a cheap and simple method to estimate LAI based on measurements of PGC in two vegetable crops with notable differences in leaf type and plant architecture; it was based on analyzing digital images obtained with a commercial camera with open-source software.

\section{Materials and Methods}

The experiments were carried out during the period 2005 to 2006 at an experimental farm located in the Vegas Bajas del Guadiana region (lat. $38^{\circ} 53^{\prime} \mathrm{N}$, long. $6^{\circ} 50^{\prime} \mathrm{W}$ ) of Extremadura (Spain); the soil was a slightly acid sandy-loam. The trial consisted of rotating two horticultural crops: cauliflower and processing tomato. The terrain was prepared in 1.5-m wide beds and was not modified over the rotation period. The cauliflower (Arbon variety) was transplanted in 5 to 7 Oct. in the first year and 12 to $15 \mathrm{Sept}$. for the second year at a density of 20,000 plants/ha in staggered twin rows. The tomato (Odin variety) was transplanted on $23 \mathrm{Apr}$. in the first year and 3 May in the second year at a density of 33,333 plants/ha in single rows. Drip irrigation was used with one irrigation line per row at a drip rate of $1 \mathrm{~L} \cdot \mathrm{h}^{-1}$ and with a distance of $20 \mathrm{~cm}$ between emitters.
The experimental design was a split plot with three complete blocks. In the main plot, two soil management regimes were used: bare soil $(\mathrm{T})$ and plastic covers (mulch) $(\mathrm{P})$ with $120-\mathrm{cm}$ wide, $25-\mu \mathrm{m}$ thick, black biodegradable matter, Mater-Bi ${ }^{\circledR}$ (Novament, Italy). In the subplot, three irrigation regimes were established for the crop evapotranspiration $(\mathrm{ETc})$ : T125 and P125 = $1.25 \mathrm{ETc}, \mathrm{T} 100$ and $\mathrm{P} 100=\mathrm{ETc}$, and $\mathrm{T} 75$ and $\mathrm{P} 75=0.75 \mathrm{ETc}$.

ETc was calculated on a daily basis from the expression $\mathrm{ETc}=\mathrm{ETo}^{*} \mathrm{Kc}$. In this formula: ETo is the evapotranspiration rate of the reference crop, calculated according to the Penman-Monteith formula modified and adapted to local conditions (Baselga, 1996) using data obtained from a weather station located near the experimental area; $\mathrm{Kc}$ is the crop coefficient for cauliflower and processing tomato (Allen et al., 1998), considering only the basal coefficients $(\mathrm{Kcb})$ for the mulched trials; and $\mathrm{Kc}=\mathrm{Ke}+\mathrm{Kcb}$ for bare soil with $\mathrm{Ke}$ being the evaporation coefficient.

Digital image processing. On each elementary plot, a $120 \times 150-\mathrm{cm}$ rectangular frame of polyethylene tubing was placed along a crop row to identify a representative area containing six tomato and four cauliflower plants. Photographs of the selected areas (elementary plot) were taken using a commercial camera (Sony Digital Still Camera DSC 828 with a resolution of 8 megapixels; Sony, Tokyo) at a height of $160 \mathrm{~cm}$ above the soil surface (Fig. 1). The data were measured at solar noon. This time was chosen after images taken at different times of the day and night confirmed that this was the best time of day because it was when the light and shadow angle conditions allowed the best possible discrimination between the crop and the soil for subsequent interpretation. Photographs were taken at 10 -d intervals with a total of 12 measurements for each crop from transplantation to harvest.

The free software GIMP 2.2 (http://www. gimp.org/downloads) was used to analyze the digital images and to differentiate between the vegetation and the soil or plastic by means of a color reclassification process. To quantify the percentage of vegetation cover, we used the methodology proposed by Campillo et al. (2008) using the reclassification method as a measure of PGC.

Measuring leaf area index. LAI was measured throughout the growing season from areas in representative plots that had previously been marked and photographed. Measurements were taken from four complete cauliflower and six complete tomato plants and measurements of the surfaces occupied by the plants were also subsequently taken. Four samples per experimental plot were made over the crop cycle. Whole plants were separated into leaves, stems, and fruits, with each being separately weighed while fresh. A sample of leaves from each elementary plot was measured in a laboratory using a planimeter (LI-3100; LI-COR Inc., Lincoln, $\mathrm{NE})$ to determine leaf area; these samples were then dried in a forced-air oven at $65^{\circ} \mathrm{C}$ to a constant weight. The dry weight of the sample and its leaf area was used to calculate total leaf area and the value of LAI was obtained from Eq. [3]:

$$
\begin{aligned}
L A I= & \frac{(\text { dry weight sampling area }(\mathrm{gr}))}{\left(\text { sampling area }\left(\mathrm{cm}^{2}\right)\right)} \\
& * \frac{\left(\text { leaf area }\left(\mathrm{cm}^{2}\right)\right)}{(\text { leaf dry weight }(\mathrm{gr})}
\end{aligned}
$$

Data analysis was carried out by means of an analysis of covariance between regressions (Peña, 1987).

\section{Results and Discussion}

Figure 2 shows the evolution (days after transplanting) of LAI and PGC under three different water doses in cauliflower (Fig. 2A) and processing tomato (Fig. 2B). In cauliflower, Figure 2A shows that only treatments altered the development of vegetation cover,

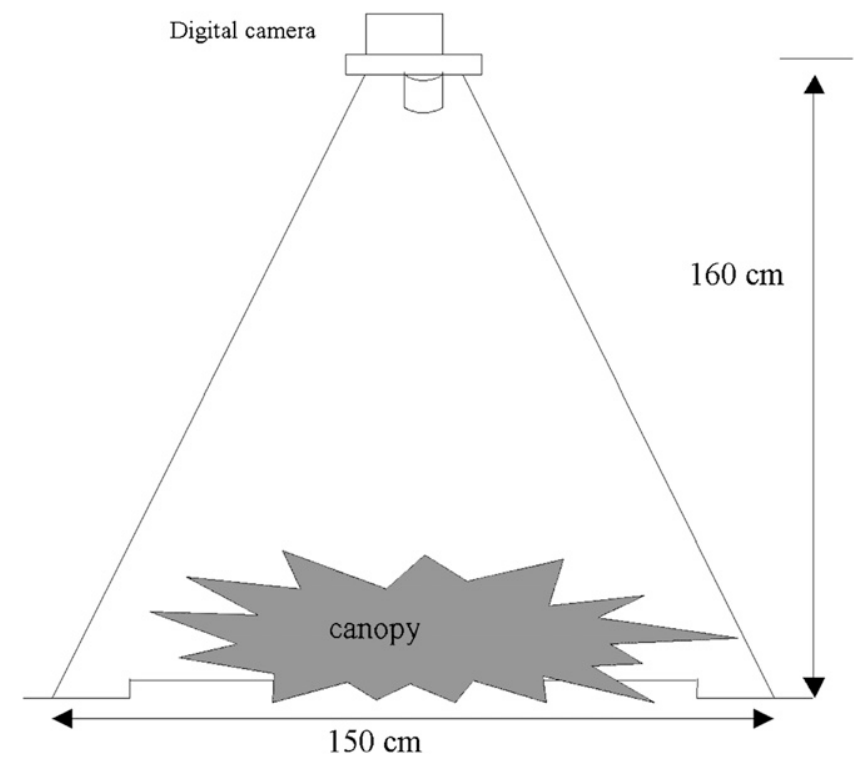

Fig. 1. Diagram of digital photography methodology over the crop. 
A

\section{CAULIFLOWER}
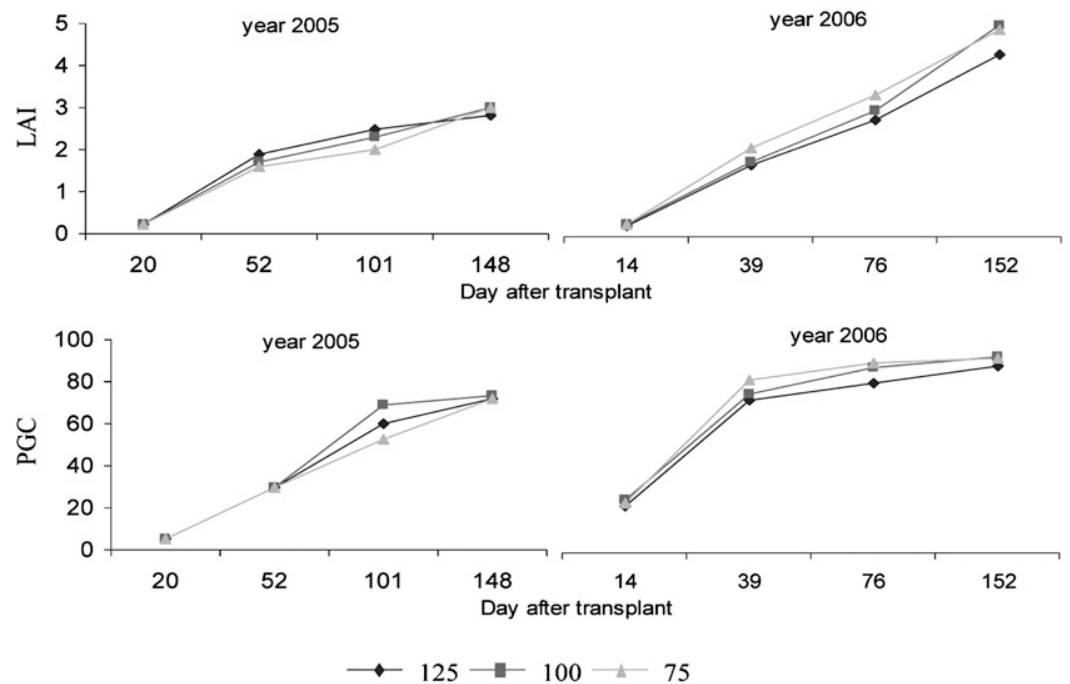

B
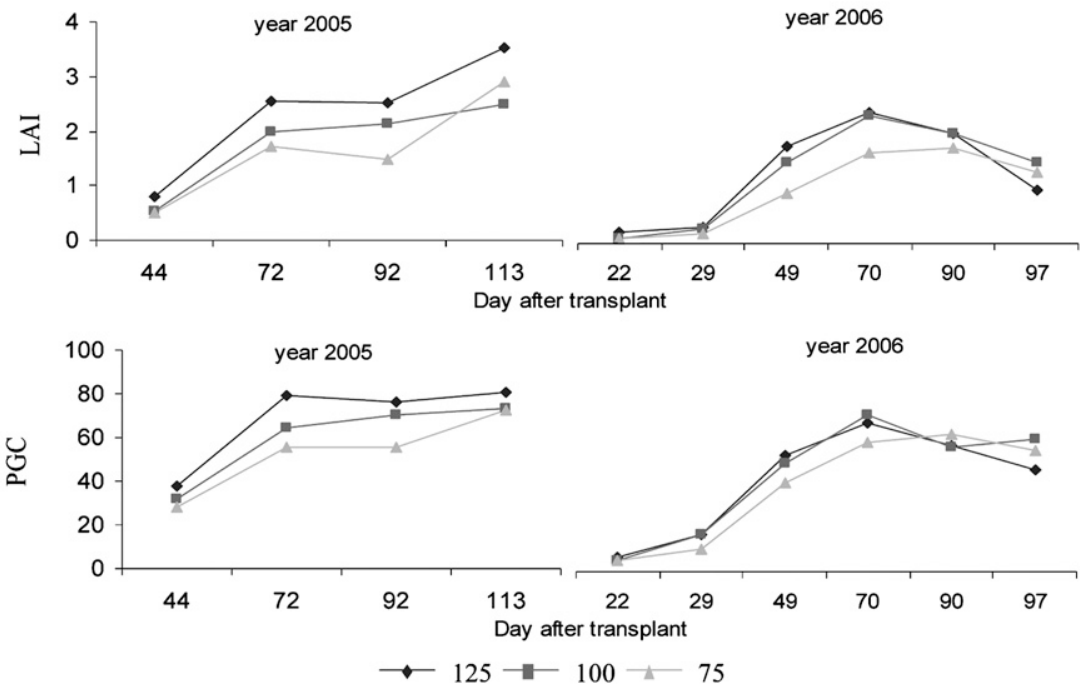

Fig. 2. Evolution of leaf area index (LAI) and percentage of groundcover (PGC) for cauliflower (A) and processing tomato $(\mathbf{B})$ for three watwer doses, $125(1.25 \mathrm{ETc}), 100(1 \mathrm{ETc})$, and $75(0.75 \mathrm{ETc})$ during the 2 years of the rotation (2005 and 2006) in terms of days after transplant. ETc $=$ crop evapotranspiration.

and no significant different changes in LAI and PGC were observed; however, there were significant differences between the 2 years; in 2005 , leaf development was significantly lower than in 2006, with higher values of PGC, maintaining the increase in leaf area until harvest. In processing tomato (Fig. 2B), significant differences were observed between treatments with lower levels of LAI and PGC in the less irrigated treatments. However, the development of this crop was similar over the 2 years of study.

Figure 3 shows the values for PGC obtained from digital images of cauliflower (Fig. 3A) and tomato (Fig. 3B) and the LAI values obtained by destructive sampling. A polynomial relationship $\left(r^{2}>0.88\right)$ was observed between the two variables in both crops. PGC increased with leaf area development in a curve-linear pattern composed of an initial linear phase followed by a saturating phase, which approached a maximum asymptotic value at full groundcover.

In cauliflower, significant differences were observed between the curves obtained for each year $\left(r^{2}=0.89\right.$ and 0.95 for the first and second years, respectively; Fig. 3A). This difference was the result of a significant change in the prevailing weather conditions during the crop cycle that affected the morphology of the leaves. Temperatures in the first year were lower than in the second and frequent frosts caused the curling of leaf margins, resulting in a lower PGC for the same LAI.

The PGC-LAI curve adjustments for the tomato crop were significant (Fig. 3B). The curves coincided for both years, although with differences in the adjustment ( 0.89 and 0.93 for 2005 and 2006, respectively). In this case, a single curve would have enabled us to estimate the LAI by nondestructive methods using digital images. Although, in principle, the factors that can modify the arrangement of leaves could alter this relationship, this trial included treatments with different water statuses that could have induced changes in plant leaf angle, but this aspect did not affect the goodness of fit. It still remains to be seen how this equation would be influenced by morphological (plant height and leaf type) differences between varieties. The PGC of a crop depends on the leaf area development and on the distribution of the plant leaves on the space (plant architecture). PGC is therefore the dependent variable in the relationship between LAI and PGC. The equations obtained for these two crops are highly significant with a narrow adjustment; they therefore provide a method for estimating LAI based on known PGC values.

From the data obtained when comparing LAI values with those of PGC, and from that obtained by Campillo et al. (2008) relating to PGC as a good estimator of RI, from Eq. [1], we obtained extinction coefficients for growing tomatoes and cauliflower with values ranging between 0.75 and 0.85 and 0.60 and 0.70 , respectively. These data are consistent with the value of 0.75 obtained by Heuvelink et al. (2005) for the cultivation of tomato and of 0.55 for growing cauliflower proposed by Olesen and Grevsen (1997). Tei et al. (1996) obtained similar extinction coefficients for other horticultural crops with morphological similarities to cauliflower such as beets and lettuce ( 0.68 and 0.60 , respectively). Campbell (1986) made an overall estimate of extinction coefficients for various crops based on the angle distribution of their leaves; considering average values for crops with leaf angles that were mainly almost horizontal, the values obtained ranged between 0.50 and 0.70 .

The data obtained by digital photography PGC allow rapid estimation of leaf area using a camera and free software obtaining LAI values in the simplest way than when measured with a planimeter carried out using destructive measure and individual leaf analysis.

\section{Conclusions}

There is a significant exponential correlation between PGC and LAI in cauliflower and tomato with an $r^{2}$ of greater than 0.89 ; that offers the possibility of obtaining non-destructive estimates of LAI from PGC values using digital images.

The method used also allows non-destructive estimations of LAI measured from complex types of cover compared with other indirect methods that are more expensive and require skilled operators.

Destructive sampling also has limitations. These include: the handling of equipment by different operators; limitations in sample size; and measurement errors in the planimetry and drying of the samples. These factors may reduce the reliability of these measures. 

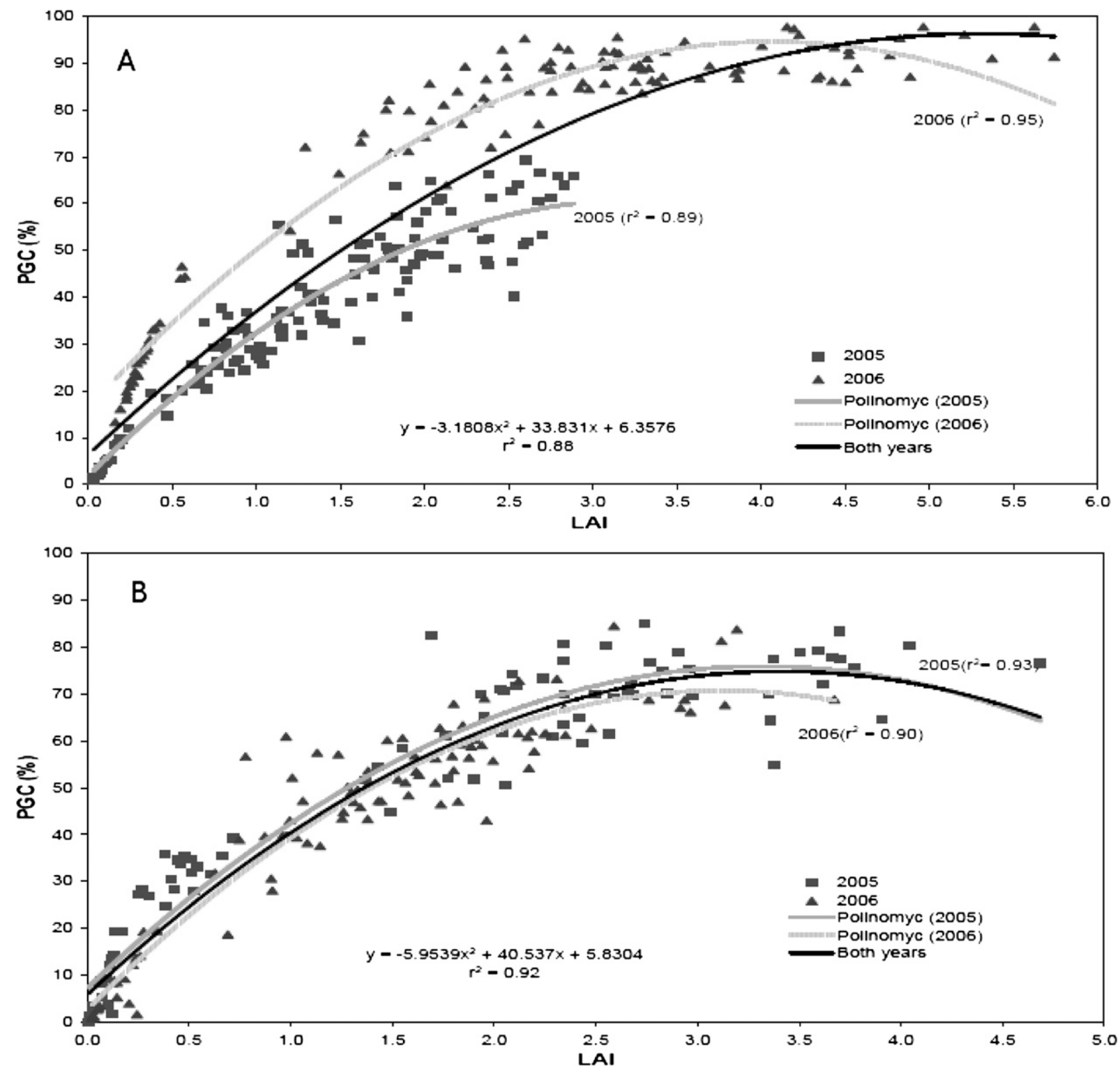

Fig. 3. Relationship between leaf area index (LAI) estimated through the destructive sampling of biomass and the percentage of shaded ground measured (PGC) by the reclassification method for cauliflower $(\mathbf{A})$ and tomato $(\mathbf{B})$ crops during the 2 years of the rotation.

\section{Literature Cited}

Allen, R.G., L.S. Pereira, D. Raes, and M. Smith 1998. Crop evapotranspiration-Guidelines for computing crop water requirements. FAO Irrigation and drainage paper 56

Baselga, J.J. 1996. A Penman-Monteith for semiarid climate in South-Western Sapin. Actas $1^{\text {a }}$ International Conference: Evapotranspiration and Irrigation Scheduling. ASAE-IA. 9991007.

Berbigier, P. and J.M. Bonnefond. 1995. Measurements and modeling of radiation transmission within a stand of maritime pine (Pinus pinaster Ait). Ann. Sci. For. 52:23-42.

Board, J.E., M. Karmal, and B.G. Harville. 1992. Temporal importance of greater light interception to increased yield in narrow-row soybean. Agron. J. 84:575-579.

Bréda, N.J. 2003. Ground-based measurements of leaf area index: A review of methods, instruments and current controversies. J. Expt. Bot. 54:2403-2417.

Burstall, L. and P.M. Harris. 1983. The estimation of percentage light interception from leaf area index and percentage ground cover in potatoes. J. Agr. Sci. 100:241-244.

Campbell, G.S. 1986. Extinction coefficients for radiation in plant canopies calculated using an ellipsoidal inclination angle distribution. Agr. For. Meteorol. 36:317-321.

Campillo, C., M.H. Prieto, C. Daza, M.J. Moñino, and M.I. García. 2008. Using digital images to characterize canopy coverage and light interception in a processing tomato crop. HortScience 43:1780-1789.

Chason, J.W., D.D. Baldocchi, and M.A. Huston. 1991. A comparison of direct and indirect methods for estimating forest canopy leaf area. Agr. For. Meteorol. 57:107-128.

Clough, B.F., J.E. Ong, and G.W. Gong. 1997. Estimating leaf area index and photosynthetic production in mangrove forest canopies. Mar. Ecol. Prog. Ser. 159:285-292.

Egli, D.B. 1994. Mechanisms responsible for soybean yield response to equidistant planting patterns. Agron. J. 86:1046-1049.

Fakorede, M.A.B. and J.J. Mock. 1977. Leaf orientation and efficient utilization of solar energy by maize (Zea mays L.), p. 207-230. In: Agrometeorology of the maize (corn) crop. Proc. Symp. Agrometeorol. Maize (corn) Crop. World Meteorology Organitation. Iowa State Univ., Ames, IA.

Gifford, R.M., J.H. Thorne, W.D. Witz, and R.T. Giaquinta. 1984. Crop productivity and photoassimilate partitioning. Science 225:801-808.

Hassika, P., P. Berbigier, and J.M. Bonnefond. 1997. Measurements and modelling of the photosynthetically active radiation transmitted in a canopy of maritime pine. Ann. Sci. For. 54: 715-730.

Heuvelink, E., M.J. Bakker, A. Elings, R. Kaasermaker, and L.F.M. Marcelis. 2005. Effect of leaf area on tomato yield. Acta Hort. 691:43-50.

Jonckheere, I., S. Fleck, K. Nackaerts, B. Muysa, P. Coppin, M. Weiss, and F. Baret. 2004. Review of methods for in situ leaf area index determination. Part I. Theories, sensors and hemispherical photography. Agr. For. Meteorol. 121 $19-35$.

Jones, H.G. 1992. Plant and microclimate. 2nd Ed. Cambridge University Press, Cambridge, UK. 
Lang, A.R.G., X. Yuequin, and J.M. Norman. 1985. Crop structure and the penetration of direct sunlight. Forest Meteorology 35:83-101.

Ledent, J.F. 1977. Sur le calcul du coeficient d'extinction du rayonnement solaire incident direct dans un couvert végétal. Oecologia Plantarum 12:291-300.

Manivel, L. and R.J. Weaver. 1974. Biometric correlations between leaf area and length measurement of 'Grenache' grape leaves. HortScience 9:27-28.

Marshall, J.D. and R.H. Waring. 1986. Comparison of methods of estimating leaf-area index in oldgrowth Douglas-fir. Ecology 67:975-979.

Millard, P., G.G. Wright, M.J. Adams, R.V. Birnie, and P. Withworth. 1990. Estimation of light interception and biomass of the potato (Solanum tuberosum L.) from reflection in the red and near-infrared spectral bands. Agr. For. Meteorol. 53:19-31.

Monsi, M. and T. Saeki. 1953. Uber den lichtfaktor inden pflanzen gesselschaften und seine bedeutung fur di estoff produktion. Japanese Journal of Botany 14:22-52.

Morgan, J.A. and R.H. Brown. 1983. Photosynthesis and growth of bermudagrass swards. I. Carbon dioxide exchange characteristics of swards mowed at weekly and monthly intervals. Crop Sci. 23:347-352.

Nel, E.M. and C.A. Wessman. 1993. Canopy transmittance models for estimating forest leaf area index. Can. J. For. Res. 23:25792586.

Olesen, J.E. and K. Grevsen. 1997. Effects of temperature and irradiance on vegetative growth of cauliflower (Brassica oleracea L. botrytis) and broccoli (Brassica oleracea L. italica). J. Expt. Bot. 48:1591-1598.

Pearce, R.B., R.H. Brown, and R.E. Blaser. 1965 Relationships between leaf area index, light interception and net photosynthesis in orchardgrass. Crop Sci. 5:553-556.

Peña, D. 1987. Estadistica. Modelos y métodos 2. Modelos lineales y series temporales. Universidad A, Madrid, Spain.

Pierce, L.L. and S.W. Running. 1988. Rapid estimation of coniferous forest leaf area index using a portable integrating radiometer. Ecology 69:1762-1767.

Rodríguez, A., A. de la Casa, R. Accietto, L. Bressanini, and G. Ovando. 2000. Determinación del área foliar en papa (Solanum tuberosum L., var. Spunta) por medio de fotografías digitales conociendo la relación entre el número de pixeles y la altura de adquisición. Revista brasileira de agrometeorología 8:215-221.

Smith, F.W., A.D. Sampson, and N.J. Long. 1991. Comparison of leaf area index estimates from tree allometrics and measured light interception. For. Sci. 37:1682-1688.

Smith, N.J. 1993. Estimating plant area index and light extinction coefficients in stands of
Douglas-fir (Pseudotsuga Menziesii). Can. J. For. Res. 23:317-321.

Tei, F., A. Scaife, and D.P. Aikman. 1996. Growth of lettuce, onion, and red beet. 1. Growth analysis, light interception, and radiation use efficiency. Ann. Bot. (Lond.) 78:633-643.

Turton, S.M. 1985. The relative distribution of photosynthetic active radiation within four tree canopies, Cragieburn Range, New Zealand. Australian Forest Research 15:383-394.

Vickery, P.J., I.L. Bennett, and G.R. Nicol. 1980. An improved electronic capacitance meter for estimating herbage mass. Grass Forage Sci. 35: 247-252.

Vose, J.M., N.H. Sullivan, B.D. Clinton, and P.V. Bolstad. 1995. Vertical leaf area distribution, light transmittance, and application of the BeerLambert law in four mature hardwood stands in the southern Appalachian. Can. J. For. Res. 25: 1036-1043.

Watson, D.J. 1947. Comparative physiological studies on the growth of field crops: I. Variation in net assimilation rate and leaf area between species and varieties, and with and between years. Ann. Bot. (Lond.) 11:41-76.

Williams, W.A., R.S. Loomis, and C.R. Lepley. 1965. Vegetative growth of corn as affected by population density. Crop Sci. 5:211-215.

Wilson, J.W. 1963. Estimation of foliage denseness and foliage angle by inclined point quadrats. Aust. J. Bot. 11:95-105. 